\title{
DESMATERIALIZAÇÃO SÍGNICA COMO PRODUTO DA ESCRITURA EXPANDIDA*
}

\author{
Wilton Azevedo*
}

RESUMO: A literatura como processo do imaginário psíquico narrativo e sua eloquência é mais conhecimento que ciência, e desta forma a linguística acaba por cumprir este estado científico com o aprofundamento da análise do código verbal e sua sintaxe. A hipermídia lança mão de outras formas de análise e uma outra maneira de se interpretar esta escritura: a digital. Esta nova escritura nos faz perceber que a característica expandida no ambiente hipermídia, destrói de vez a ideia de que as linguagens são constituídas de sistema matricial, para isso, ressalto a importância do poema processo de Wlademir Dias Pino (1972) não só como percussor da imaterialidade da palavra, mas principalmente de colocar o poema processo como fator antecipado da escritura em expansão.

PALAVRAS-CHAVE: Hipermídia. Poesia.

O que é o cérebro humano, senão um palimpsesto imenso e natural? Meu cérebro é um palimpsesto e o vosso também, leitor. Grandes camadas de ideias e imagens, de sentimentos, caíram sucessivamente sobre o vosso cérebro, com a mesma suavidade da luz. A impressão era de que cada uma sepultava a precedente. Mas nenhuma perece, na realidade.

(Charles Baudelaire)

Sabemos que a escrita humana nasceu sobre as pedras, e para cravar estes sinais cifrados, fomos obrigados a ter ao nosso lado a tecnologia do estilete levando a cabo a palavra estilo para os dias de hoje. Da mesma forma, como o rolo de papiro era belo de se admirar e extremamente difícil para ser guardar, utilizar, e com tamanho limitado para armazenar, a criação tecnológica nunca deixou de ser dispensada para que pudéssemos escrever.

Este registrar trouxe para a humanidade uma cultura mnemotécnica, e passamos a adquirir conhecimento sem a necessidade de ter que memorizá-las, ou muitas vezes

\footnotetext{
* Originalmente publicado na revista Texto Digital, volume 3, número 1, 2007.

** Universidade Presbiteriana Mackenzie, São Paulo, Brasil.

\section{(cc) EY-NC-ND}

Esta obra está licenciada com uma licença Creative Commons. 
sem conhecê-las presencialmente, pois bastava recorrer novamente ao que estaria cravado, escrito - códice. (O’DONNELL, 2000, p. 62).

A ideia de códice foi uma das primeiras tecnologias da escrita que permitiu que pudéssemos acessar um texto de nossa preferência, sem necessariamente termos que nos utilizar de métodos lineares e não lineares através das escolhas dos capítulos. Para isso a paginação e a possibilidade de uma escolha reativa sobre o meio, não é e nunca foi privilégio dos sistemas digitais.

Com isto observamos que muito do que pensamos ser privilégio da linguagem hipermídia, não o é. O codex já possibilitava a:

a) A não linearidade

b) Sistemas reativos para escolha de textos.

c) A intertextualidade, o dialogismo com outros códigos.

d) A possibilidade da oralidade e o dado móvel verbal. Ou seja, nada disso é novidade por causa do mundo digital.

Como aponta James O'Donnell (2000), mesmo com a invenção da imprensa e com todas as suas mudanças tecnológicas da reprodução, não conseguimos mudar algumas coisas essenciais deste suporte que é o livro,

\begin{abstract}
Apesar de que hubo interrupciones profundas, la comunidad fundamental de productores e usuários de textos permaneció bastante fija: el clero e los aristocratas. Algunos ex monjes se convertieron seguramente em profesores de universidad (Lutero es um ejemplo claro), pero la continuidad de la comunidad de textos se intensifico al máximo. El códice conservo la forma externa del libro y las técnicas que explotaron su poder em los últimos años de uma cultura exclusivamente manuscrita fueron perfeccionadas y no sustituidas (O'DONNELL, 2000, p. 49-50).
\end{abstract}

A poesia hipermídia, Interpoesia, nos paira ainda como algo a ser descoberto pelo seu exercício experimental do ato de fazê-la, mas este fazer não pode estar apenas nas práticas tecnológicas de software para software, em um uso constante na intenção de mostrar sua versatilidade, e sim o fazer crítico, para não deixar perecê-la pela novidade. 
As experiências sempre foram abertas no sentido do dialogismo entre a mesmice e o estranhamento, e desaparecendo este conflito depois da linguagem digital pairar como suporte da produção poética, tem hoje um espaço internacional contemporâneo, principalmente depois dos poemas concretos.

Mas com certeza não foram apenas estes passos dados com muito trabalho que nos colocou no mapa internacional da poética e tecnologia. É óbvio que não.

O que tem faltado no Brasil é uma ampla discussão sobre poética e o que nos trouxe para o campo do suporte digital a praticar esta forma de poesia e poemas ainda não esclarecidos através de pesquisas. Com grandes equívocos, sem sepultarmos o que já foi feito, não vejo ultimamente por parte das principais instituições de pesquisa, trazer a poesia digital no Brasil para um plano não apenas de visibilidade, mas principalmente de crítica e discussão, a um lugar que com todo mérito já nos fazemos respeitados no exterior.

Se quisermos enterrar de vez o que deixamos de pesquisar, sugiro que o façamos em lugar certo. Começando pelos exercícios lexicais das legendas em forma de palavras e logografias preconizado por Wlademir Dias Pino no poema Processo ${ }^{1}$, os poemas holográficos executado por Moysés Baumstein e Fernando Eugênio Catta-Pretta, traduzindo poesia concreta para o espaço virtual, os poemas sonoros e visuais de Philadelpho Meneses, e os poemas-lasers de Augusto de Campos em 1991, raios lasers de traduzidos para o éter junto com Haroldo de Campos, para então tentarmos entender quais são os poetas e as poesias que operam a mídia digital em seu amplo sentido hipermidiático.

O uso da tecnologia em poemas de autores brasileiros, não se detecta em seus manifestos, e sim no caminho natural que estas formas poéticas foram tomando, o que torna mais difícil um recorte teórico em saber quais destas correntes

\footnotetext{
1 Alerto que para toda citação referente a Wlademir Dias-Pino, seu livro Processo: Linguagem Comunicação. Editora Vozes, Petrópolis, Rio de Janeiro, não tem referência de ano e nem número de página, o que torna difícil a fonte. Este livro, segundo o autor me disse em entrevista concedida no Rio de Janeiro em março de 2006 no Hotel Othon Leme, é de 1972.
}

Texto Digital, Florianópolis, Santa Catarina, Brasil, v. 12, n. 1, p. 226-239, jan./jun. 2016. ISSNe: 1807-9288. 
preconizaram o conceito de hipermídia antes que se pensasse o software como forma de produção poética.

Fig. 1 e 2 - Sequência do Atame: A Angustia do Precário - 2007 - Wilton Azevedo - (UnderLab).

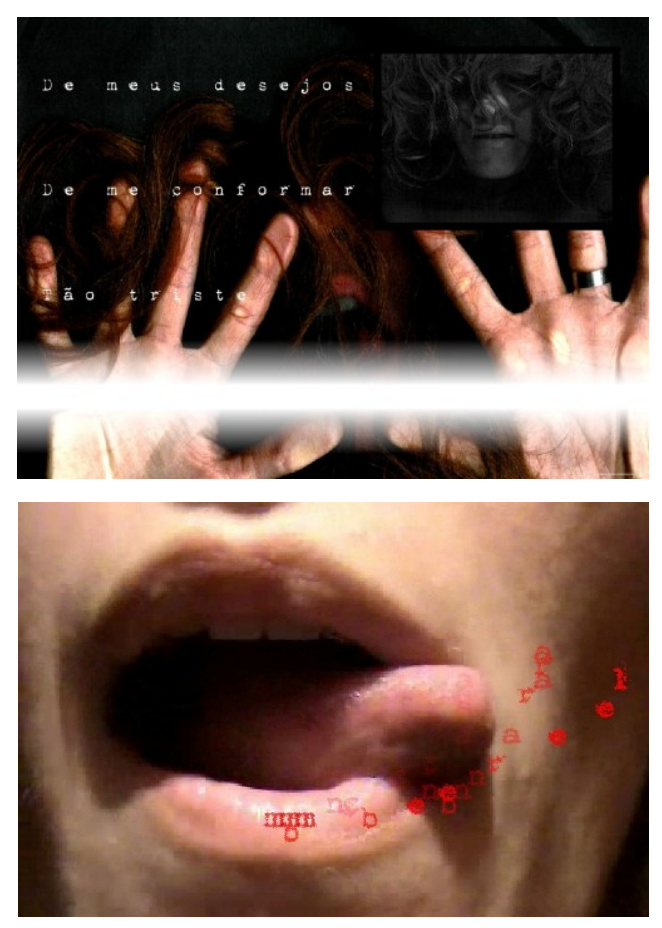

Não é minha preocupação neste texto, este levantamento histórico, espero que um dia alguém o façam de maneira correta, mas em apontar a verdadeira importância para um recortes relevantes de nossa poesia, que foi o surgimento do Poema Processo como forma primordial da antevisão dos sistemas ideogramáticos da hipermídia.

Quando realizei o Interpoesia (1997) sabia que este trabalho fora gerado em um sistema que levava em consideração muito mais o ponto de vista de sua escritura do que da escrita, mais próxima ao poema processo e seus conceitos, do que a um nicho específico noigandrezianio ${ }^{2}$ e a própria poesia concreta pertencente a outros poetas que acabaram por ficar a margem.

\footnotetext{
2 Aqui me refiro ao grupo NOIGANDRES criado por Augusto de Campos, Haroldo de Campos e Décio Pignatari. de 1952 e é dessa data o surgimento da Revista Noigrandes 1 . O lançamento oficial da Poesia Concreta foi em 1956, e o Plano Piloto para Poesia Concreta é de 1958.
}

Texto Digital, Florianópolis, Santa Catarina, Brasil, v. 12, n. 1, p. 226-239, jan./jun. 2016. ISSNe: 1807-9288. 
Quando menciono tecnologia em poesia, não estou falando de realidade virtual, e nem tão pouco de cinema interativo ou disponibilização em rede para pratica interativa, estou chamando a atenção para a importância do fazer poético no suporte digital detectando o que possibilitou a transição entre: a escrita e sua oralidade, e a imagem potencializada em sua mutação, e o som como movimento espacializado, tudo contido em um sistema de escritura expandida.

Esta nova escritura nos faz perceber que a característica de uma escritura em expansão destrói de vez a ideia de que as linguagens são constituídas de sistema matricial, por isso ressalto a importância do poema processo:

Segundo Dias-Pino, o poema processo ${ }^{3}$, "é aquele que a cada nova experiência, inaugura processos informacionais (...) o poema resolve-se por si mesmo, desencadeando-se (projeto), não necessitando de interpretação para sua justificação".

E continua,

\begin{abstract}
Poema processo é a consciência diante de novas linguagens [...] Não se trata, como alguns poderiam pensar, de um combate rígido $r$ gratuito ao signo verbal, mas de uma exploração planificada das possibilidades encerradas em outros signos ( não verbais). A leitura é conseguida pela transparência do papel , desenvolvida até a transparência total que é a perfuração. Ao tratar do problema da transparência atinge-se uma problemática oposta de superposição de informação: isto impede a figuração pelo excesso de ruído que causaria.
\end{abstract}

\footnotetext{
${ }^{3}$ Em 1956 Dias-Pino trás como novidade informacional o livro AVE em que a proposta era criar "uma leitura sem intervalos: "O livro recebeu um tratamento de máquina, com suas folhas soltas, perfuradas, cortadas, codificada em séries etc., quase ao ponto de ser um computador de bolso."
}

Texto Digital, Florianópolis, Santa Catarina, Brasil, v. 12, n. 1, p. 226-239, jan./jun. 2016. ISSNe: 1807-9288. 
Fig. 3 - Po e-Machine 2006. Wilton Azevedo (UnderLab).

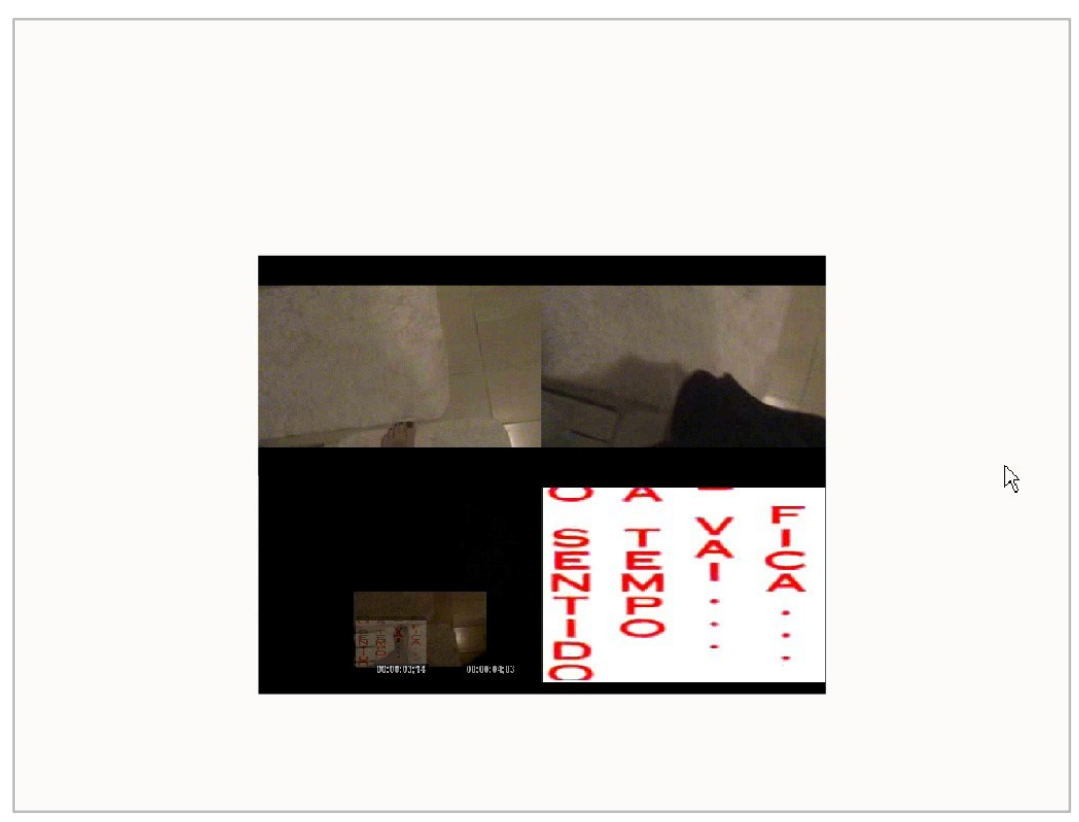

A ideia de abrir a poesia no transito de novas conquistas tecnológicas faz parte da exegese poética, nesta direção que Philadelpho Meneses propunha incessantemente a ideia da poesia intersignos, uma poesia que se utilizasse principalmente de componentes gráficos e sonoros, o que deu origem alguns anos depois à prática deste conceito na hipermídia no CD-ROM Interpoesia: Poesia Hipermídia Interativa (2000) de nossa autoria, e também no Looppoesia (2004).

As especificidades dos sistemas de linguagem no que chamamos tradicionais e o que conhecemos como digitais tornaram cada vez mais evidente, que falar de produção de linguagem e sua disseminação é falar de um complexo tecnológico, isto porque, um código sempre vai precisar de uma tecnologia que o sustente. Em termos semióticos para ser disseminado, o que antes era visto; como aparato tecnológico intermediador, hoje podemos perceber que é parte de uma escritura interpoética: "Technically, for Landow, hypertext can be defined as a technology of text put into a web that can make clear the intertextuality inherent in literary works" (MENESES; AZEVEDO, 2004, p. 200). 
Para analisarmos estas mudanças, teremos que levar em consideração um argumento que defendo desde o Colloquium de Cerisy La Salle em $2004^{4}$, organizado por Jean Pierre Balpe e Manuela de Barros, que tudo que adquirimos por meio da linguagem digital tem o sentido de produção de articulação sígnica. Não há mais a manipulação em termos de montagem, tudo nesta escritura em expansão é articulado. A linguagem digital coloca a produção da linguagem em uma nova escala alfabética - de escrita mas que envolve gerenciamentos em que a máquina é parte integrante desta articulação.

O método usado para percebermos este articular sígnico é o da prática poética nos ambientes da hipermídia, e é aí que percebemos os autores que trabalham a tecnologia como escritura e aqueles que por problema de formação vêem a poesia nestes ambientes como pratica tecnológicas e acabam confundido escrita digital com escritura digital.

Chamemos então a atenção para a atemporalidade destes produtos de poéticas digitais. Não há nada a ver com o conceito de codex; quem escolhe estes ambientes da hipermídia apenas para escrever e criar textos como informação - datum - está criando um banco de dados, o que é uma pequenina parte do conceito de hipermídia.

Na realidade esta pratica, como dizia Meneses (2004), "[...] trespasses the limits of the verbal sign itself" (2004, p. 201).

Este exercício de composição em que faz surgir formação sígnica que se integram para se para se expandir, faz com que as diferentes linguagens desapareçam formando uma espécie de pulsar e quasar da linguagem humana, porque não há aqui uma tecnologia que media ou inter media, e sim uma tecnologia que insere e intervém, alterando os signos como processo em sistema de escritura, os dados - datum - como parte de um sistema, e a articulação dos algoritmos - mathematic models - como poesia. Se não conseguirmos ver por este ângulo, estaremos perdendo um tempo enorme em reviver o "já feito" apenas de maneira mais precisa.

\footnotetext{
${ }^{4}$ Este texto esta publicado em L'art a-t-il besoin du numérique? Colloque de Cerisy . Org. Jean Pierre Balpe e Manuela Barros. Lavoisier, Paris. 2006.
}

Texto Digital, Florianópolis, Santa Catarina, Brasil, v. 12, n. 1, p. 226-239, jan./jun. 2016. ISSNe: 1807-9288. 
A programação passa a ser parte integrante desta escritura, em que os três códigos predominantes se integram quando pensamos em um método para realizá-lo, e se expandem quando começamos a programá-los. O resultado final é um produto que não conta histórias, não nos traz para a sensação do signo admirável, não há imagens inteiras, ou seja, há um núcleo de signos se expandindo criando um corpo virtual que existe potencialmente como poética, mas nunca estará pronto, definido, acabado ou reconhecido, e isto para a espécie humana que crivou sinais e inventou tecnologias para seu memorial passa a ser difícil de aceitar.

Os aspectos culturais quanto à credibilidade da compreensão e a produção de conhecimento estavam ligados apenas à tecnologia da escrita, como questiona Alberto Manguel (1997). Assim, veremos que as tentativas de uma prática semiótica nos tornam atentos ao fato de que o código verbal, como agente articulador de signos - software -, fez mudar seu referencial de arbitrariedade deste "vir a ser" histórico como forma de registro. Com o mundo da escritura numérica advindo da cultura dos suportes digitais, a linguagem verbal, que tem como modelo um alfabeto, teve sua práxis há muito transformada na obtenção para o que chamar de conteúdo analítico. Com esta tradição, notamos que o algoritmo nada mais é do que uma escritura que, a cada dia, deixa de ser um modelo matemático de simulação, passando à condição de intercódigo hipermídia ou escritura expandida. (AZEVEDO, 2004, p. 7).

\section{DESMATERIALIZAÇÃO E MEMÓRIA}

Com isso a poesia hipermídia estabelece mais que uma relação entre relação os códigos e seus registros, sonoro, verbal e visual, passamos a notar que as justaposições de palavras passam a não ter vínculo com uma estrutura sintática tradicional, este sacrifício de inteligibilidade que se nota por este fazer poético - a priori - é apenas um índice desta articulação de linguagem e sua leitura pode ser feta de acordo com a capacidade de memorização das sequências e seu aspecto de não interinidade. 
Os meios digitais estão autorizando cada vez mais esta poética, a interdependência mútua e a responsabilidade compartilhada entre leitor e poeta, e poesia, a exploração deste novo processo, nada tem a ver com o sistema antes impresso.

Neste mesmo sentido já histórico o conceito de desmaterialização segue um novo rumo no tocante à memória, o que compreendíamos como modo de transmissão do saber e do conhecimento, começa a sofrer mudanças nas atividades intelectuais.

O fato da escrita se desmaterializar e sua multiplicidade ter como limite um moto perpetum em sua escritura, traz o fazer poético e sua aquisição estarem agora não mais a serviços de: manifestos, grupos de poetas e artistas, e sim na expansão que essa linguagem passa a ocupar em sua rede, tendo a máquina como coeficiente da escritura expandida, sem horário estipulado, sem instituição para sua credibilidade, e sem que os vencedores tenham seus textos como tabula rasa, é um outra forma de expressão que dispensa o conceito equivocado de híbrido, é uma escritura que vai em sentido contrário da aglutinação para sua visibilidade, é um sistema semiótico que traz para o que chamamos até então de abstração, só que ao se expandir no ambiente da hipermídia não se faz mais a necessidade de distinguir mais o fazer e o abstrair esta distinção passa a ser mesma coisa.

Fig. 4 - Po e-Machine (memória) 2006. Wilton Azevedo (UnderLab).

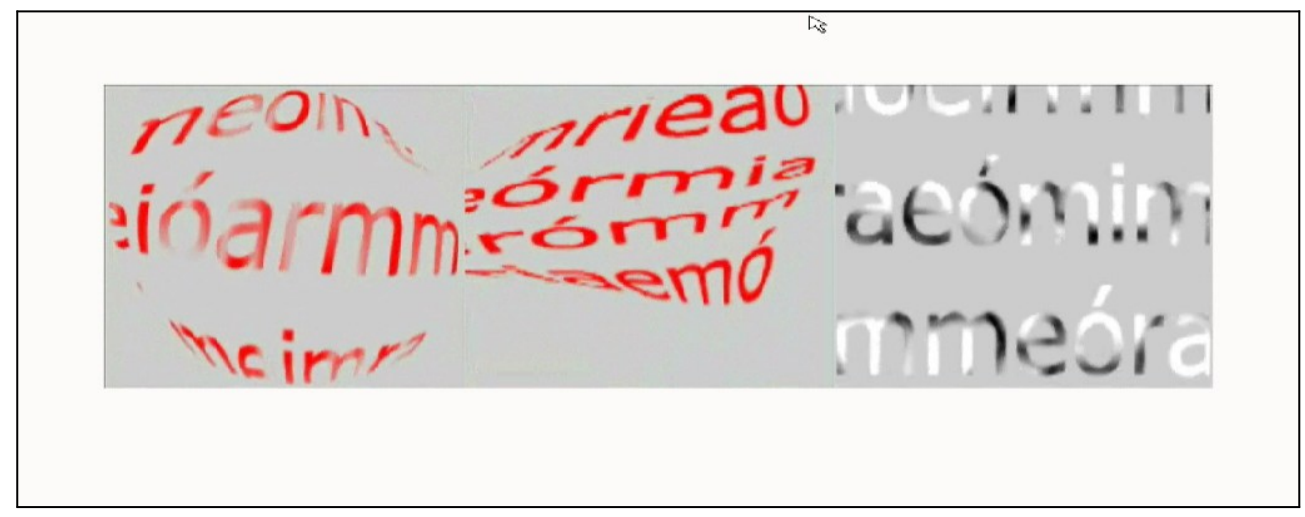




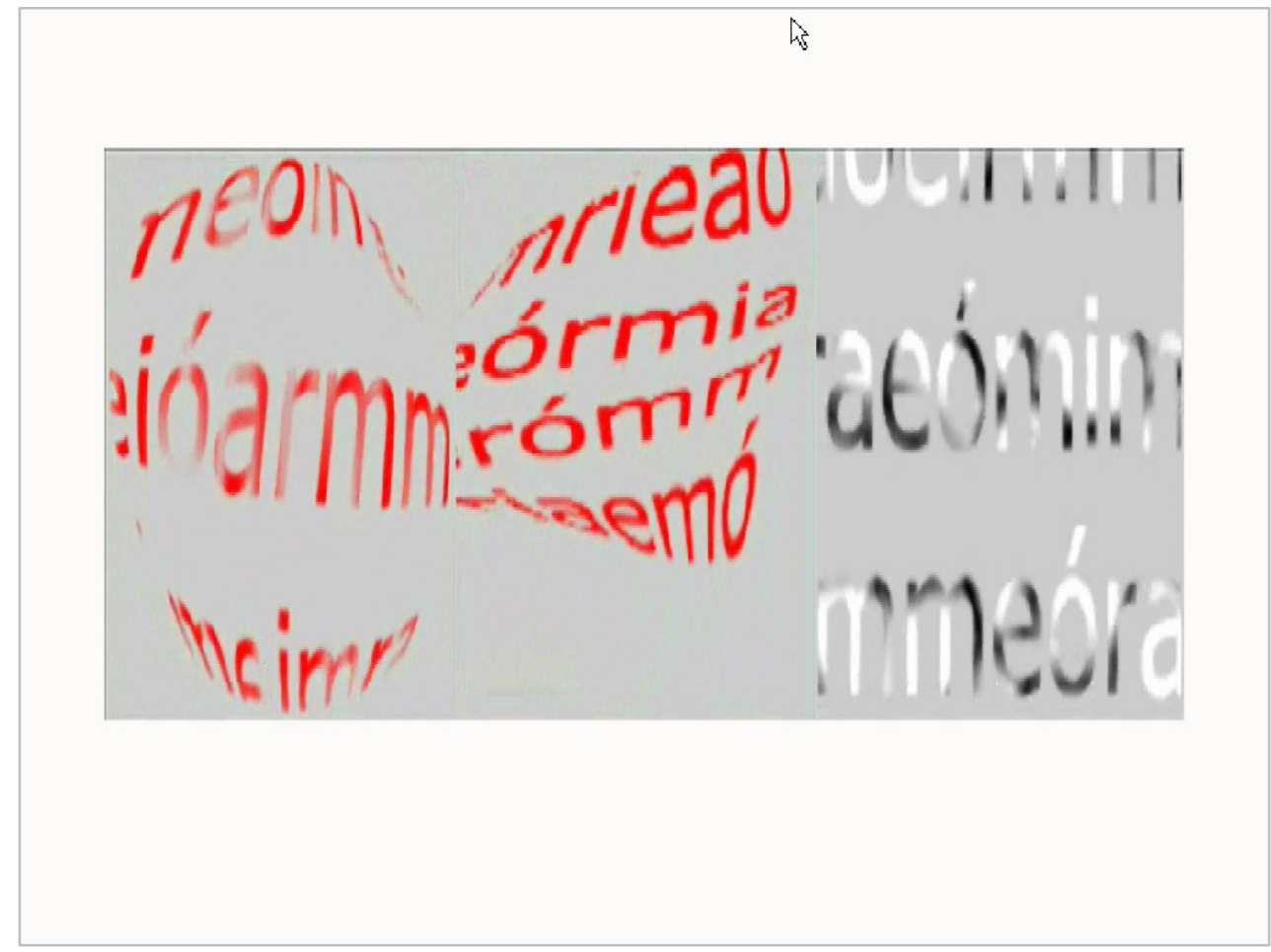

Assim o conceito de interpoesia traz para o sentido poético, questões que antes estavam destinados apenas para a filosofia, como a aquisição do saber e a do conhecimento. No ambiente da hipermídia, estes conceitos encontra a ambiência ideal para uma pratica intelectual, mas agora este produto não se faz da eloquência finita de nossa fala ou de argumentos de retórica, e sim em uma meta discurso, ou melhor, um interdiscurso dispensando a cultura da impressão: "Cést douze ou treize siècles avant la nouvelle technique que le livre occidental trouve la forme qui demeurera la sienne dans la culture de l'imprimé" (CHARTIER apud DUCARD, 2004, p. 124).

Sem dúvida toda a cultura virtual ligado ao significado de uma palavra, desde Sausurre, se torna imperativo com a numeralização algorítmica do texto, é um avatar que se apresenta de maneira ilimitada como escreve Ducard (2004, p. 124), citando Paul Valéry: Machine à lire.

\section{PO E-MACHINE: A MÁQUINA DA DESMATERIALIDADE POÉTICO}


Fig. 5 e 6 - Performance Pó e-Machine no FILE -Festival Internacional de Linguagem Eletrônica 2006. (Imagem 1 e 2).
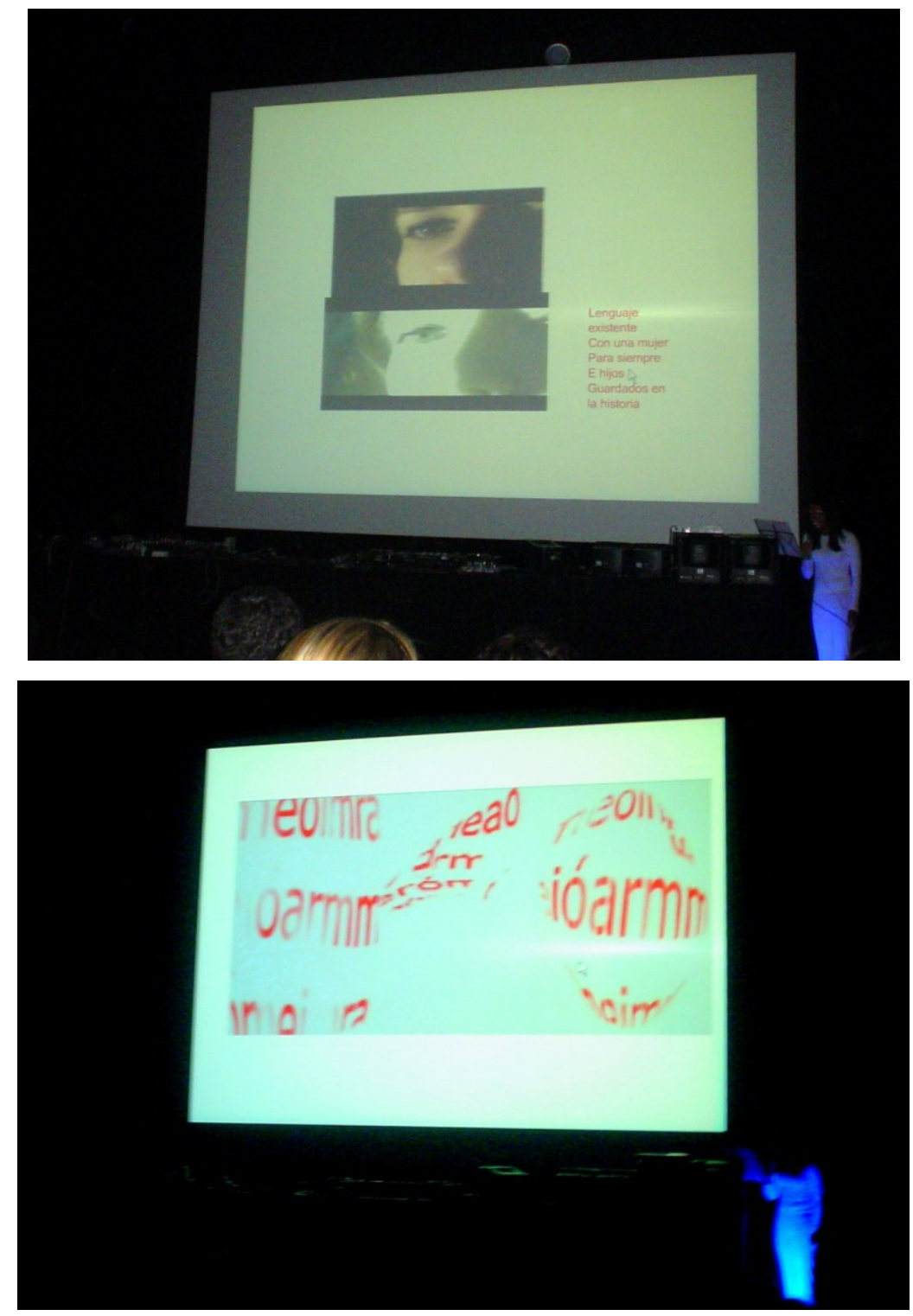

Em janeiro de 2006 comecei a trabalhar em um novo conceito de interpoesia performática. A ideia do Pó e-Machine é trazer os sistemas interativos em uma só escritura expandida mais que um diálogo - parte em tempo real, parte prégravado (samplers) - fazendo parte do coeficiente poético em suporte digital e seu ambiente "do provável". 
Fig. 7 a 12 - Sequência do Po e-Machine 2006. Wilton Azevedo (UnderLab).
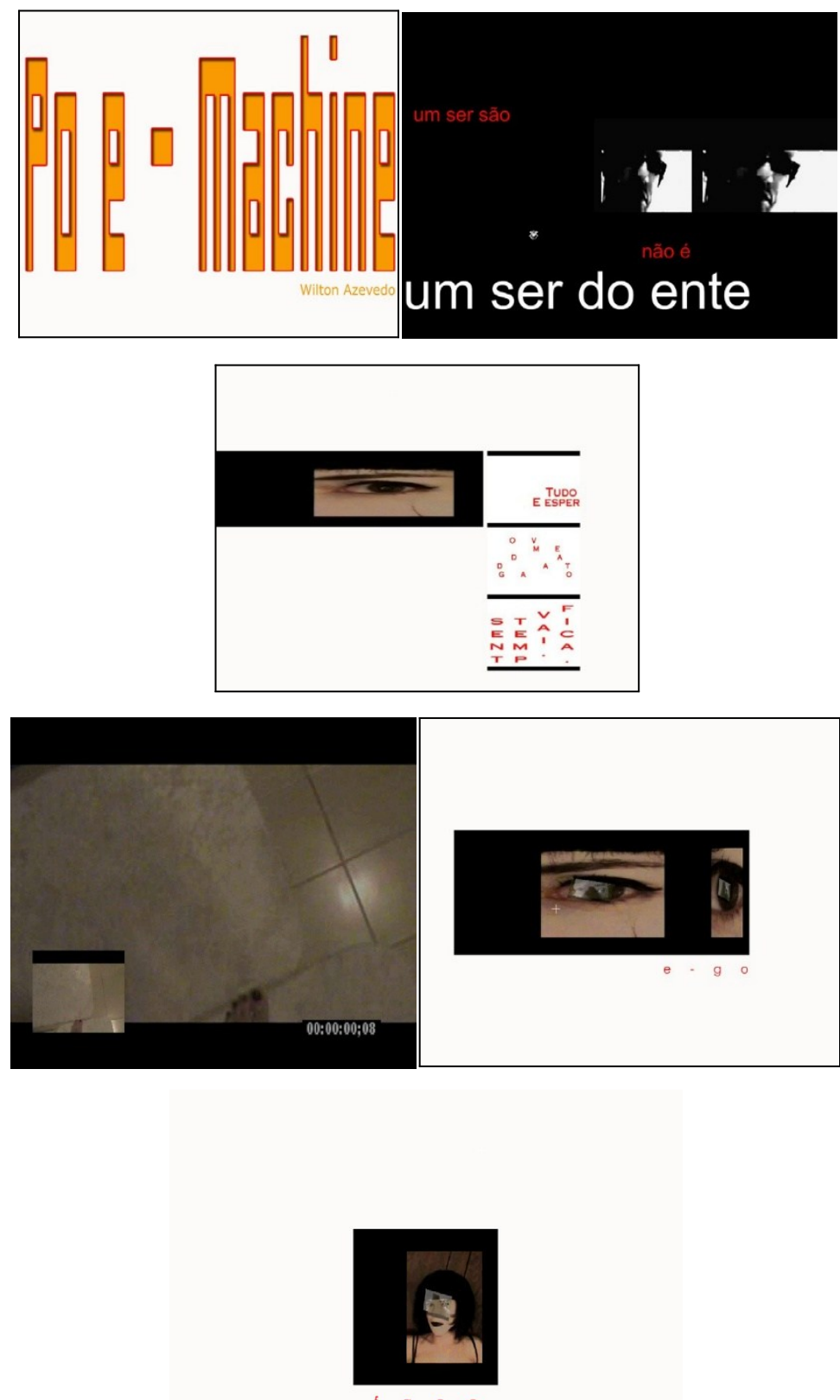

A montagem do Pó e-Machine ${ }^{5}$ envolve quatro etapas:

1. A leitura de poemas desconstruídos em tempo real.

2. Poemas sonoros pré-gravados no estúdio e sampleados em tempo real.

\footnotetext{
5 Po e-Machine foi apresentado no Hipersônica 2006, evento este que faz parte do FILE - Festival Internacional de Linguagem Eletronica em São Paulo no Teatro do SESI dia 18 de agosto de 2006. Teve como equipe: Raquel Rava no vocal, Thais Ernandes na voz sampleada, Rita Varlesi na execução dos vídeos digitais, Savana na programação e interfaces, Wilton Azevedo, direção e autoria: www.estudiounderlab.co
}

Texto Digital, Florianópolis, Santa Catarina, Brasil, v. 12, n. 1, p. 226-239, jan./jun. 2016. ISSNe: 1807-9288. 
3. Vídeos, textos e sons interativos em um formato que dialogue com a leitura em tempo real e o som sampleado.

4. No computador há sons que se permutam com vozes Pré-gravadas.

Esta montagem exigiu um sentido de articulação, pois conta com o tempo real como uma "fala", um poema vivo, articula e gesticula signos em movimentos na tela e se complete com a leitura e os sons sampleados com vídeos e textos inseridos ao mesmo tempo durante a apresentação.

\section{SIGNICAL DEMATERIALIZATION AS A PRODUCT OF EXPANDED WRITING}

ABSTRACT: Literature as a process of the psychic narrative imaginary and its eloquence is more knowledge than science, and in this manner linguistics carry out the scientific state with the examination of the analyses of the verbal code syntax. Hypermedia utilizes other forms of analyses and another ways of interpreting this writing: the digital. This new writing brings us to perceive that the expanded characteristic in the hypermedia environment destroy the idea that languages are constructed from a matrix system, for this, I emphasize the importance of Wlademir Dias Pino's process poem (1972) not only as the precursor of the word's immateriality, but mainly by placing the process poem as an anticipated factor of writing in expansion.

KEYWORDS: Hypermidia. Poetry.

\section{REFERÊNCIAS}

Azevedo, Wilton. Textes poétiques hypermédia: un écrit en expansion. In: BALPE, P. JEAN; BARROS, Manuela de (Orgs.). Lárt a-t-il besoin du numérique?. Colloque de Cerisy. Paris: Lavoisier, 2006, p. 201-12.

Dias-Pino, Wlademir. Processo: linguagem \& comunicação. Petrópolis: Vozes, 19--.

Ducard, Dominique. De mémoire d'hypertexte. In : Roelens, Nathalie ; Jenneret, Yves. L'IÍmaginaeire de L'ÉEcran/ Screen Imaginary. Edition Rodopi B. V. Amsterdam, 2004.

Meneses, Philadelpho ; Azevedo, Wilton. Interactive poems: intersign perspective for experimental poetry. In: Roelens, Nathalie; Jenneret, Yves. Límagineire de L'Ecran/ Screen Imaginary. Edition Rodopi B. V. Amsterdam, 2004. 
O'Donnell, James. Avatares de las palabras: del papiro al ciberespacio . Editorial Paidós, Buenos Aires, 2000. 